\title{
Periferia de la periferia. Sobre el papel de las exposiciones colectivas en la definición del arte caribeño contemporáneo
}

\author{
Periphery of the Periphery. About the role of collective \\ exhibitions in the definition of Contemporary Caribbean Art
}

\author{
Carlos Garrido Castellano \\ Universidad de Granada \\ Carlo_garrido@hotmail.com
}

Recibido: 14 de octubre de 2011

Aprobado: 7 de marzo de 2012

\begin{abstract}
Resumen
El presente artículo se aproxima a la realidad del arte contemporáneo del Caribe a través de las exposiciones colectivas de arte caribeño que se generan en la década de los noventa y que constituyen uno de los elementos que con mayor fuerza vertebran la conexión entre los discursos de la región. Para ello, se atenderá a la problemática actual de la curaduría artística, entendida como una práctica cultural que se convierte en instrumento de mediación social. Asimismo, se analizarán las prácticas curatoriales que contribuyeron en la década de los noventa a definir una determinada imagen del Caribe y de su producción artística, estableciendo los vínculos entre dichas experiencias curatoriales y los escenarios locales e internacionales en los que se desarrollan. La exposición colectiva, fenómeno que prolifera a partir de los noventa en el Caribe, constituirá el principal difusor de la cultura caribeña fuera de su territorio, al tiempo que contribuirá a generar un sentimiento de cohesión dentro del archipiélago.
\end{abstract}

Palabras clave: Arte Contemporáneo; Caribe; Curaduría artística; Exposiciones colectivas; Identidad

Garrido Castellano, C. (2013): Periferia de la periferia.Sobre el papel de las exposiciones colectivas en la definición del arte caribeño contemporáneo. Arte, Individuo y Sociedad, 25(1) 65-75

\begin{abstract}
The present article focuses on analyzing the reality of Contemporary Caribbean Art through the collective exhibitions generated during the Nineties, one of the elements that have contributed more clearly to the creation of links between the artistic practices of the region. In order to do that, some issues concerning curatorship, understood as a cultural practice able to work as an instrument of cultural mediation, will be examined. Moreover, it will be paid attention to the curatorial practices that have contributed to define certain image of the Caribbean and of its art, establishing the relation between those curatorial experiences and the local and international scenarios where they take place. The collective exhibition, phenomena that arise during the Nineties in the Caribbean, will be the main element of diffusion of Caribbean artistic cultures outside its borders, generating at the same time a cohesive influence between the territories that conform the region.
\end{abstract}

Key Words: Caribbean [region]; Collective Exhibitions; Contemporary Art; Curatorship; Identity.

Garrido Castellano, C. (2013): Periferia.Sobre periphery of the role of exhibitions in the contemporary Caribbean art definition. Arte,Individuo y Sociedad 25(1) 65-75 
Sumario: 1. Introducción. Curaduría artística e identidad, 2. Ubicando el arte contemporáneo del Caribe, 3. La exposición colectiva de arte caribeño: morfología, 4. La exposición colectiva de arte caribeño: discursos y pertenencia, 5. Conclusiones, Referencias.

\section{Introducción. Curaduría artística e identidad}

Este artículo recoge resultados de una investigación centrada en torno a las relaciones artísticas y culturales en el ámbito caribeño contemporáneo que surge en el contexto del Proyecto de Excelencia "Andalucía en América: Arte, Cultura y Sincretismo Estético (P07-HUM 03052)". Con el presente trabajo se pretende deconstruir una categoría, la de arte contemporáneo caribeño, a partir del análisis de uno de los elementos que mayor repercusión tuvieron en la constitución de aquél: las exposiciones colectivas que marcaron la evolución de lo que se entendía por arte caribeño a partir de la década de los noventa del siglo XX. Ello quiere decir, en cierto modo, que dichas imágenes, históricamente construidas a partir de un diálogo dentro-fuera, entre las escenas artísticas nacionales y la integración en el panorama internacional, condicionaron la producción, la distribución y la exposición de la práctica artística, de tal modo que resulta necesario aproximarse a esa realidad para entender cualquiera de esos elementos.

Las preocupaciones asociadas a la curaduría artística, entendida como fenómeno cultural amplio y abarcador, se han visto sustancialmente transformadas en las últimas dos décadas. Cuestiones asociadas al rol del artista como configurador del discurso expositivo y como agente curatorial, a la función de la bienal como evento cultural o la pertinencia de su multiplicación y diseminación por todo el globo, o a la interpretación de la exposición artística como fenómeno comunicacional o como espectáculo mediático, han permeado el debate crítico, modificando la manera de concebir la exposición de la práctica artística. La figura del curador o comisario, al tiempo que ha adquirido preponderancia con respecto a otros agentes que forman parte del sistema artístico, ha ampliado y diversificado sus funciones, haciendo posible hablar de un "giro curatorial" de la práctica artística (O' Neill, 2007, p.15).

Dichas modificaciones en el debate crítico en torno a la curaduría han venido aparejadas de otro fenómeno no menos interesante: la apropiación del espacio del museo por parte de las sociedades de la periferia que, de este modo, han conseguido en las últimas dos décadas incorporarse-no sin ciertas contradicciones-al imaginario artístico occidental. Así, han sido múltiples las voces que han analizado la relación entre la práctica curatorial, el público receptor de ésta y la capacidad de lo expuesto para "representar" otras culturas. Mari Carmen Ramírez (1996) habla de la transformación del curador, entendido como árbitro del gusto, en el curador que ejerce como mediador cultural. Para la autora, ese cambio ha supuesto una apertura decisiva del espacio artístico internacional: "This shift of curatorial function, in turn, seems to have opened up new venues for the distribution, acceptance, and appreciation of previously marginalized art." (Ramírez, 1996, p.16).

A partir de estas premisas, este artículo se aproxima al contexto del arte contemporáneo del Caribe con el objetivo de analizar el pensamiento curatorial expresado a través de las muestras colectivas regionales que se suceden sin 
interrupción a partir de 1990, determinando su función en la configuración de una identidad artística regional. Las exposiciones de arte caribeño resultarán vitales en el contexto del archipiélago por varios motivos: en primer lugar, constituyen el escenario en el que se producen los primeros intentos por generar un sentimiento de integración pan-caribeña en las artes visuales; asimismo, en ellas se manifiestan, con mayor claridad que en los debates artísticos nacionales, las transformaciones que sufre la representación de la región, así como la apuesta, cada vez más decidida, por la modernidad artística y la conexión con lo producido en el sistema artístico internacional; en tercer lugar, las exposiciones colectivas celebradas en el Caribe se convirtieron en verdaderos acontecimientos de interés regional, que atrajeron una cantidad de público infinitamente superior a la que tradicionalmente puede vincularse al fenómeno artístico en el archipiélago caribeño; por último, este proceso ha venido aparejado del desarrollo de instituciones y organismos que han impulsado la creación y la exhibición en los distintos territorios que conforman el Caribe.

Los condicionantes culturales y políticos que marcaron los años noventa hicieron del arte un elemento imprescindible en el desarrollo de las culturas caribeñas, tanto en la definición de la identidad nacional como en la configuración de nuevas cartografías y nuevos lazos culturales; la Bienal de La Habana, instituida en una fecha tan temprana 1984, puede ser un buen ejemplo de ello. En el momento en que estaban siendo repensadas las relaciones de poder y la geografía de dichas relaciones, en que se reactiva el debate sobre los sistemas de dominación y su influjo en los productos culturales, el Caribe se convierte en un centro, en un laboratorio,en un espacio germinativo (Wood, 1998, p.37), al que se dirigen las miradas del resto del mundo.

\section{Ubicando el arte contemporáneo del Caribe}

A principios de la década de los noventa el Caribe ocupaba una posición periférica dentro de la realidad artística americana. Si durante los ochenta el arte latinoamericano negociaba su posición respecto al Mainstream, consiguiendo integrarse en el contexto europeo y estadounidense, el Caribe permanecería ajeno a ese movimiento, quedando como una porción inexplorada del continente. Periferia de la periferia, no sería hasta la década de los noventa cuando, coincidiendo con diversos procesos históricos y culturales - la caída del muro, la conmemoración del Quinto Centenario del Descubrimiento de América - se produzcan los primeros intentos de configurar un arte caribeño, integrando la producción artística de países que hasta el momento habían permanecido inconexos. En esa década, pues, aparece un interés creciente por analizar la producción creativa del Caribe, coincidiendo con la emergencia de ciertas inquietudes en el panorama teórico internacional, tales como la definición identitaria, el postcolonialismo o la revisión del multiculturalismo. En ese marco, el Caribe, bajo la observación atenta de todo el planeta, se convierte en el laboratorio perfecto para examinar el mundo desde una posición que deviene de nuevo central sin dejar de ser excéntrica.

Alejado de los circuitos internacionales del arte, sometido a serias carencias en la infraestructura artística, el Caribe será construido a partir de las grandes exposiciones 
centradas en la producción de la región. El interés de la comunidad internacional por cartografiar un área otra dentro de la otredad del continente americano coincidirá con un proceso de búsqueda identitaria presente en todo el territorio caribeño. Ahora surge, tanto en el interior como en el exterior de la región, la conciencia de que existe un imaginario compartido en el Caribe, y la certeza de que ese imaginario podía aportar elementos de interés válidos para comprender no sólo los procesos culturales que estaban teniendo lugar en el espacio Caribe, sino para acercarse al resto del planeta.

Junto a esa conciencia común—que, no lo olvidemos, ha de entenderse más bien como comunidad de problemas, como imaginario compartido, que como superación de las distancias y las desigualdades existentes en el archipiélago caribeño - se configura ahora por vez primera una clase curatorial que paulatinamente conseguirá trasladar las inquietudes del debate artístico y cultural caribeño al ámbito internacional. En efecto, a principios de los noventa el arte constituía una industria cultural marcadamente nacional en el Caribe. No sólo porque gran parte de la producción artística creada en la región se consumiera en los lugares en los que era producida; también debido a que la falta de instituciones impedía al artista negociar su posición con cierta autonomía fuera de los límites de su propia comunidad. Es cierto que existían excepciones, y que un nutrido grupo de artistas había iniciado en los ochenta el camino que derivaría en una mayor apertura en los años noventa; sin embargo, el panorama que encontramos a nivel general en toda la región es el de sistemas artísticos nacionales. Es en ese entorno en el que el artista tenía que negociar su posición respecto a la sociedad y el sistema artístico locales.

La situación comenzará a cambiar de manera paulatina al comienzo de la última década del siglo. Si bien es cierto que con marcadas diferencias entre unas islas y otras, se desarrolla en ese momento un diálogo que negociará la posición del Caribe dentro de un marco más amplio; al mismo tiempo se genera una conciencia entre los actores del panorama artístico de pertenecer a un cuerpo mayor, que se extiende a lo largo de todo el territorio caribeño. De este modo, las fronteras que pudieran marcar la lengua, la cultura o la situación política piden parte de su eficacia ante el empuje de iniciativas colectivas que tienen entre sus principales objetivos generar un sentimiento de cohesión. Al mismo tiempo, se produce un desarrollo institucional sin precedentes: se crearán nuevos museos y centros de arte, surgirán maneras alternativas de entender la práctica artística (ahora se multiplican los workshops y se generan las primeras experiencias pan-caribeñas en el performance) y se reformulará la función de las instituciones ya existentes. Es el caso, por ejemplo, del Museo de Arte Moderno de Santo Domingo, que en 1992 pasa a concebirse como un centro vinculado al arte contemporáneo de la región, dando lugar ese mismo año a la primera edición de la Bienal del Caribe y Centroamérica.

Dentro de este panorama marcado por los cambios constantes y por la modificación de horizontes, los artistas abordarán de una manera consciente su posición como creadores de la periferia. Si el arte del Caribe ha sido asociado en varias ocasiones con la resistencia (Walcott, 1995), no puede obviarse el hecho de que, en numerosas ocasiones, dicha postura ha venido aparejada de una búsqueda de las raícessumergidas - de las innumerables mezclas que conforman las comunidades caribeñas 
(Nettleford, 1995), proceso que ha derivado en un cuestionamiento del papel del tráfico cultural y poblacional intercontinental en la definición de las sociedades modernas (Gilroy, 1993).

En definitiva, en los noventa se producen dos procesos estrechamente conectados entre sí: por un lado, en la región caribeña se configura un espacio expositivo regional, acompañado de cierto desarrollo institucional; por otro, el arte del Caribe desborda los límites del archipiélago, alcanzando las costas del arte occidental. Las exposiciones colectivas de arte caribeño resultarán vitales en ambos aspectos.

\section{La exposición colectiva de arte caribeño: morfología}

Las experiencias que vertebraron el discurso del arte contemporáneo caribeño a partir de la década de los noventa no fueron homogéneas. No existió un único modelo de muestra colectiva, al igual que no existió una única posición respecto a lo que se consideraba representaba la identidad artística de la región. El panorama del momento estará protagonizado por bienales internacionales y regionales, grandes exposiciones colectivas organizadas tanto desde dentro como desde fuera del Caribe, y por nuevas experiencias como talleres de creación o itinerarios artísticos que se extendieron de un país a otro contribuyendo a reforzar los vínculos entre los artistas caribeños. La diversidad morfológica de las iniciativas se vería reflejada asimismo en los programas curatoriales. Entre los objetivos y el funcionamiento de la Bienal de La Habana y los de una exposición de arte caribeño celebrada en un país europeo, por ejemplo, existe no sólo un distanciamiento en su concepción, sino también en su repercusión en la práctica artística de la región. En todo caso, la participación en las muestras colectivas servirá a los artistas como trampolín a partir del cual trascender las limitaciones de la esfera artística nacional. En muchas ocasiones, así, la participación de un artista en un evento internacional desembocaría en la inclusión en las muestras periódicas del país o del archipiélago.

La condición insular será, precisamente, percibida como seña identitaria caribeña, siendo una de las principales preocupaciones de la crítica de la región el cómo integrar la cuenca continental. En efecto, si bien el interés por abarcar la totalidad del Caribe llevaría a algunas de las exposiciones colectivas de principios de los noventa-Carib Art (1991), la primera Bienal del Caribe de Santo Domingo (1992), pueden servir de ejemplo - a defender una visión basada en la cuenca del Mar Caribe, la gran mayoría de propuestas de la década basarían sus criterios de selección en el concepto de antillanidad o en el de insularidad, generando así una diferenciación con respecto a la dinámica del continente. No faltarán, sin embargo, experiencias conjuntas: así, el performance servirá, por ejemplo, de elemento conector vital para desarrollar una zona de contacto entre Centroamérica y las partes continental e insular del Caribe.

Si atendemos al funcionamiento de las exposiciones, encontraremos una diversidad aun mayor. El arte caribeño contemporáneo se construye a través de un proceso de creación, descubrimiento y diálogo, que surge y se desarrolla en permanente dinámica dentro-fuera, de tal manera que la imagen de réplicas y múltiples influencias y apropiaciones en ambos sentidos, puede dar una visión acertada del devenir del proceso. En el que quizá sea el único trabajo al respecto, Yolanda Wood acierta a 
plantear dos niveles - desde dentro y desde fuera — en los que se desarrollará el fenómeno del arte caribeño, señalando su tendencia anti-hegemónica como uno de los elementos comunes (Wood, 2000, p.15). Es necesario, sin embargo, destacar la estrecha conexión entre ambos niveles.

La relación con el público, la itinerancia y el sistema de cuotas constituyen los principales elementos de utilidad a la hora de categorizar el funcionamiento de las muestras de arte caribeño. En primer lugar, la adaptación al lugar donde se realiza la exposición, sea éste perteneciente al área caribeña, a Europa o a Estados Unidos, condicionará la selección de los participantes y la presentación de las muestras. La nómina de artistas que intervienen en este proceso será, sin embargo, bastante homogénea a lo largo de la década, algo que puede explicarse por la participación de entidades e individuos procedentes de los países caribeños en las iniciativas internacionales. En todo caso, el panorama exhibido en exposiciones celebradas en el Caribe no variará demasiado con respecto al de experiencias realizadas en el ámbito internacional.

La itinerancia, por su parte, será un anhelo presente desde el comienzo. Ya Carib Art (1991), considerada la muestra que abre el ciclo de colectivas de arte caribeño, se plantea como una iniciativa entre dos islas, Aruba y Curaçao. El principal modelo en este aspecto será Ante America (1992), exposición curada por Gerardo Mosquera, Rachel Weiss y Carolina Ponce de León que incluyó por vez primera de manera sistemática el arte caribeño en los discursos del arte latinoamericano y transitó entre Estados Unidos y varios países del continente. El proyecto Cariforo, comisionado por la Unión Europea y vertebrado en torno a tres centros situados en diferentes países caribeños, concibió la circulación de las obras de arte que formaban parte de sus proyectos expositivos como una de las bases de su política cultural (Tolentino, 1999). Las dificultades para mover las exposiciones en el área caribeña han de relacionarse con los problemas existentes en la situación institucional de la región, así como con la realidad política y económica de muchos territorios del Caribe, algo que dotaría a cada evento de un aura excepcional, de acontecimiento único que posibilitaba el encuentro pancaribeño. Más recientemente, a finales de la primera década del siglo XXI, muestras como Horizontes Insulares o The Global Caribbean han sido expuestas en varios países caribeños, continuando con esta tradición.

El sistema de cuotas, finalmente, se justificaba dentro de la voluntad integradora que observamos en los primeros años de los noventa. Las cuotas implicaban una representación equitativa de todos los territorios caribeños, independientemente de su tamaño, desarrollo cultural o tradición artística en aras de un mayor acercamiento entre las posiciones existentes en la zona. Si atendemos a la gran disparidad de la producción artística del Caribe, donde encontramos centros de arte que han desarrollado una actividad ininterrumpida durante siglos junto a otros que apenas tienen unas décadas de independencia política y actividad cultural en lo que al arte contemporáneo se refiere, se entenderá cuál sería el principal problema de este modelo de selección. Las cuotas, además, no tienen en cuenta que lo contemporáneo no existe en ese momento en muchas islas, y que la relación con la posmodernidad resultaba diferente en cada isla: los ochenta habían significado un mundo en algunas islas como Cuba, República Dominicana o Jamaica y una anécdota en otras. Incluso las 
propias iniciativas que adoptaron esta posición reconocieron que "algunas islas [...] no "supieron" participar." (Tolentino, 1992, p.20) Generar las condiciones para que ese "saber participar" pudiera darse; es decir, la posibilidad de encontrar un lenguaje común en el que se pudiera producir el diálogo intrarregional, protagonizaría gran parte de los discursos desarrollados en torno al cambio de siglo.

\section{La exposición colectiva de arte caribeño: discursos y pertenencia}

¿Qué Caribe fue el que se representó en las primeras muestras colectivas? Lo cierto es que las imágenes generadas surgieron condicionadas por dos realidades: la falta de visualización internacional-El Caribe seguía siendo, en gran medida, un territorio ignoto, donde plasmar los deseos y estereotipos-y la falta de acercamiento y el desconocimiento mutuo en el interior de la región. En todo caso, las miradas sobre el Caribe que expresaron las exposiciones fueron evolucionando, si bien, lógicamente, no lo hicieron de manera homogénea. Las primeras muestras colectivas de arte caribeño que tienen lugar en los años noventa están ligadas a la búsqueda de valores en torno a los cuales construir la identidad del arte caribeño.

En ese gran inventario expositivo que se dilata durante toda la década, uno de los principales caballos de batalla vendrá dado por la necesidad de establecer categorías que puedan aprehender una producción extremadamente heterogénea, en la que convivían propuestas cercanas a los lenguajes más contemporáneos y el arte naïf, recreaciones identitarias y experiencias de intercambio. La definición de un lenguaje propio, o lo que es lo mismo, el establecimiento de la posición que el espacio insular del Caribe ocupaba con respecto a la Modernidad y a la Historia, surgía como eje vertebrador de las experiencias de la década, ofreciendo las más variadas respuestas en forma de discursos creativos y de proyectos curatoriales. Ello equivalía a plantear de manera crítica en qué manera se producía el consumo de la periferia por parte de Occidente, así como a categorizar la voluntad de encontrar un mayor espacio de representación dentro del espacio del sistema artístico internacional. La integración regional e internacional, la autenticidad y la celebración de la identidad y la creatividad caribeñas, fueron cuestiones a revisar en cada exposición, en cada esfuerzo, con resultados dispares.

En Carib Art, la muestra que inaugura la sucesión de exposiciones colectivas de los noventa, ya se adivina la voluntad de construir una identidad artística pan-caribeña. La medida que materializaría dicha aspiración fue el sistema de cuotas. En efecto, se pensaba que sólo a partir de la participación igualitaria de todos los países del Caribe se podría generar ese imaginario común: "The second issue we had to deal with was the quota for every participating country. Our philosophy from the start had been to give a fair chance and an equal opportunity to each participating country and to avoid especially that the more powerful countries would take a dominant position." (Ekmeyer y Elstak, 1993, p.5). Dicha opción derivó en notables diferencias cualitativas que vinieron a sumarse a las provocadas por la exclusión de medios artísticos como la fotografía, el performance o la instalación que por esa fecha centraban el debate artístico caribeño. Organizada en 1991 por CARICOM en Aruba y Curaçao, 
la iniciativa incluía una conferencia, celebrada en Curaçao, una exposición itinerante, que daría nombre a todo el proyecto, y la publicación de un volumen crítico.

Sería, sin embargo, en 1992, cuando los discursos identitarios mejor quedaran plasmados. En el año de la conmemoración del Quinto Centenario se organizaron dos exposiciones muy diferentes en su planteamiento e intereses, pero vinculadas por su voluntad de afrontar la integración regional. 1492/1992: un nouveau regard sur les Caraïbes, trasladaba la evolución reciente de la creatividad caribeña a París, y lo hacía mediante la reivindicación del concepto de creolité. La creolité aparecía como la cultura original, formada del cruce de las influencias americanas, europeas y africanas. De esa mezcla se derivaba la riqueza cultural antillana, diferenciable de las manifestaciones del resto del continente merced a su identidad. Lo identitario se concibe como algo estable, que ha sido perpetuado a lo largo de los siglos (el curador habla de la necesidad de "sachons rester nous-mêmes" (Bocquet, 1992, p.5)), y que se muestra de forma activa en la constitución del hombre caribeño. Ello dará lugar a la posibilidad de hablar de una estética créole, en la que la producción artística desempeñará un papel fundamental, esencial, al estar asociada de manera cuasi genética al ser caribeño (Bocquet, 1992, p.6).

De mayor trascendencia en la región resultó la celebración de la Primera Bienal de Pintura del Caribe y Centroamérica, que tuvo lugar en Santo Domingo en 1992. La muestra, que suponía la plasmación de una iniciativa del CARICOM, recogía el testigo de eventos precedentes como la Bienal de La Habana y la Trienal Poligráfica de San Juan con el objetivo de generar un encuentro puramente caribeño. Se trata, por tanto, de la primera bienal regional, (dado que tanto la Trienal Poligráfica de San Juan como la Bienal de La Habana sobrepasaban el ámbito caribeño y latinoamericano), un proyecto multitudinario (en la primera edición participaron más de 300 artistas de casi 30 países) vinculado a los ideales de solidaridad y fraternidad pan-caribeña y pan-americana del Quinto Centenario. La Bienal entronca así con las políticas culturales pan-americanas llevadas a cabo por el Presidente Balaguer en la época, quien justificará la iniciativa destacando los vínculos que unen a los países del área caribeña y centroamericana: "Todos somos hermanos y compromisarios en la identidad y en la diversidad de nuestros pueblos, en su pasado, en sus penas y en sus miserias, y en sus alegrías y esperanzas de bienestar, de libertad, de redención" (Herrera, 1992, p.13).

La Bienal tendrá entre sus objetivos el desarrollo de la modernidad artística. No bastaba, pues, el refugiarse en una visión idealizada e inmóvil de la identidad; la práctica artística de la región debía afrontar su situación actual, en la que la conexión intrarregional no esté reñida con la configuración de una estética que resulte inteligible en el resto del mundo. Uno de los elementos más destacados del encuentro, así como de las ediciones siguientes, vendrá dado precisamente por esa voluntad de buscar lo contemporáneo, huyendo de visiones más celebratorias del pasado. Se afronta, así, la necesidad de trascender el dilema entre modernidad y tradición, integrando en el debate cuestiones relativas a la representación de lo caribeño y a la fuerza de los estereotipos: "De hecho existe otra pintura en el Caribe y Centroamérica, fuera de la pintura primitiva. Solo que muy pocos ejemplos se han podido ver y conocer más allá de los bordes insulares. Esa pintura se identifica con el espacio de una realidad local y una realidad universal. Todo cromado por una especie de intervención poética que 
define una necesidad de identidad planetaria, o sea más allá de los confines locales y regionales." (Rodríguez, 1992, p.18)

Paulatinamente, sin embargo, se irá advirtiendo el peligro de esa posición, al tiempo que se producían acercamientos a la realidad contemporánea del archipiélago. Así, a finales de la década, Caribe Insular: Exclusión, fragmentación y paraíso, una exposición comisariada por Antonio Zaya y María Llüísa Borràs en 1998 en el Museo Extremeño e Iberoamericano de Arte Contemporáneo (MEIAC), incidiría en las discontinuidades de la cultura caribeña. La iniciativa sentaría las bases para el modelo de exposiciones que encontraremos en la década siguiente, al tiempo que planteaba un planteamiento adecuado que por primera vez permitía afrontar el estudio de la producción artística caribeña desde una perspectiva que tenía en cuenta los conflictos de la realidad del archipiélago. En este caso, el resultado de la exposición parte de la constatación del reto que supone hablar del Caribe, tanto por la diversidad de la región como por las dificultades sociales y económicas de ésta, así como, finalmente, por la falta de estudios que hubieran puesto en común la producción de cada territorio. Asimismo, la exposición supondría una expansión al imbricar de manera estrecha la problemática del arte producido en el Caribe con su relación con referentes globales, algo que Yolanda Wood (1998, p.39) resumió afirmando que "El arte se enraíza y propaga las realidades insulares."

Podría pensarse, sin embargo, que el desplazamiento de la muestra del MEIAC se trata de una postura concebida fuera de la región; sin embargo, dentro de ésta también se observarán indicios que llevan a relativizar la importancia de lo identitario a favor de un mayor interés en los lenguajes creativos. La renovación de la Bienal de Santo Domingo, que pasó a incluir todos los lenguajes artísticos a partir de su cuarta edición, o la función de abanderada de nuevas propuestas que desempeñó la Bienal de La Habana a lo largo de toda la década, son indicadores de ello. Nos encontramos, así, con varias perspectivas que coinciden en un elemento: la necesidad de complejizar la visión curatorial del Caribe, huyendo de toda postura complaciente con la realidad actual de la región. Del Caribe integrador de las exposiciones de principios de los noventa, en el que la unidad de todos los territorios de la región bajo la exaltación de la feracidad creativa del artista caribeño, se pasará paulatinamente a un Caribe fragmentario (de nuevo, la exposición del MEIAC funcionará como paradigma).

Para el cambio de milenio el arte del Caribe había conquistado todos los territorios a su alcance, incluidos los templos sagrados de Kassel y Venecia. Pese a los numerosos intentos, el exotismo, sin embargo, la búsqueda de una definición de lo que era el arte caribeño, seguía estando presente como una herencia que debería ser abordada en la década posterior. La expansión del arte caribeño había venido aparejada a su definición, pero el proceso había quedado inconcluso. Si algo quedaba claro después de diez años de exposiciones era la enorme heterogeneidad del material de trabajo con que contaba el curador, y la obligatoriedad de dar una forma a dicho material.

A partir del 2000 la norma vendrá dada por exposiciones que son antes un tema, una introspección, que un recuento (habrá excepciones). Atrás quedaría el utópico sistema de cuotas, la mezcla desenfrenada de amateurismo y lenguaje internacional, y la identificación país-cultura-artista. Las dos vías (no excluyentes) de la búsqueda del mito, del pasado, y de la búsqueda de la modernidad marcaron una de las décadas más importantes para la cultura caribeña. 
Aunque no se puede decir que la inquietud identitaria desaparezca ante la fecha mítica del 2000, en lo sucesivo veremos una mayor conciencia en torno a la posición que toma el artista para hablar a un contexto que ya nunca más será puramente local. Los artistas que marcaron las exposiciones de los noventa fueron (amén de un buen número de gente que "pasaba por allí"), en gran medida, los mismos que habían luchado desde los ochenta por desalojar el espacio para eso que pronto se llamó Caribbean Art. Los artistas del 2000 serían, en gran medida, los triunfadores, los herederos del 90. En el 2000 las exposiciones de arte del Caribe serían otra vía más de expansión para el artista; en el 90 eran la única vía posible para muchos. O lo que es lo mismo: Pensarse dentro de un circuito regional pasó de ser una necesidad a ser una opción más en un repertorio mayor.

\section{Conclusiones}

$\mathrm{Al}$ igual que sucediera con tantas invenciones de la música caribeña a lo largo del siglo XX, el arte se convierte a finales de siglo en un elemento de exportación, en una marca que se consume desde Europa y Estados Unidos. Lo hace a través de vías y caminos ya diseñados, en los que el arte caribeño transita "a su manera", readaptando su significado a nuevas audiencias o, utilizando palabras de Gerardo Mosquera (2010, p.42), "globalizando la globalización". Sin embargo, además de la inclusión o la representación, incluso en mayor medida, el verdadero caballo de batalla de la producción de los noventa será la participación y el diálogo. De ahí que las exposiciones que tienen lugar fuera del Caribe hayan de verse no sólo como una presentación de lo caribeño fuera de sus fronteras, sino como una penetración en terrenos vedados hasta el momento que abre puertas y genera posibilidades de contacto no sólo con la sociedad "local", sino con muchas otras.

En este punto, la exposición colectiva aparece como práctica cultural amplia, que trasciende los límites de las artes visuales para convertirse en un acontecimiento de importancia regional. Se trata, por tanto, de una práctica transnacional, que utiliza el rebranding de la tradición generado por el interés que despiertan las culturas caribeñas para gestionar su posición, para crear lazos. En cierta medida, no sólo el arte caribeño, sino también, en un sentido más general, las culturas caribeñas, son modeladas en los eventos artísticos que pueblan el fin de siglo. El hecho de que el Caribe constituya una región compleja, de difícil definición geográfica y cultural, enormemente fragmentada, otorga mayor relevancia a esa acción integradora.

La importancia de las muestras colectivas de arte caribeño se evidencia si atendemos a lo inmediatamente anterior y a lo inmediatamente posterior. El panorama de los ochenta se muestra esencialmente nacional, con conexiones establecidas por cada país hacia afuera. La práctica artística de los noventa conseguirá que, a partir del 2000, exista una conciencia de pertenecer a un colectivo, al tiempo que permitirá la circulación fluida de referentes visuales entre los distintos territorios del Caribe. Se trata, por tanto, de una década-bisagra, de un periodo de efervescencia constructiva cuyos frutos sólo ahora se están dejando ver con claridad.

Agradecimientos: Este trabajo plasma el resultado de varias estancias de investigación en centros artísticos y académicos del Caribe que tuvieron lugar entre febrero 
de 2010 y junio de 2011. Hemos de agradecer la colaboración desinteresada y la acogida brindada por la National Gallery of Jamaica, el Museo de Arte Moderno de Santo Domingo (República Dominicana), el Centro Wifredo Lam y la Universidad de La Habana (Cuba) y la Direction Régionale des Affaires Culturelles (DRAC) (Martinica). Asimismo, el presente texto surge en el marco de la realización de un Proyecto de Excelencia "Andalucía en América: Arte, Cultura y Sincretismo Estético (P07-HUM 03052)", a cuyo equipo pertenecemos

\section{Referencias}

Bocquet, P. (1992). 1492/1992. Un nouveau regard sur les Caraïbes. París: Créolarts. Ekmeyer, R. y Elstak, F.A. (1993). Carib Art. Willemstad: UNESCO.

Gilroy, P. (1993). The Black Atlantic. Modernity and Double Conciousness.

Cambridge: Harvard University Press.

Herrera, P. (ed.) (1992). Primera Bienal de Pintura del Caribe y Centroamérica.

Santo Domingo: Museo de Arte Moderno.

Mosquera, G. (2010). Islas infinitas. Sobre arte, globalización y culturas. En Olivares,

R. (Ed.), Gerardo Mosquera. Caminar con el diablo: Textos sobre arte, internacio nalismo y culturas (27-45). Madrid: Exit Books.

Nettleford, R. (1995). Caribbean Cultural Identity. En Lewis, S. y Hewitt, J. (Eds.), Caribbean Visions. Contemporary Painting and Sculpture (37-43). Alexandria, Art Services International.

O’Neill, P. (2007). The Curatorial Turn: from Practice to Discourse. En Rugg, J. y Sedgwick, M. (Eds.), Issues in Curating Contemporary Art and Performance (1328). Chicago: University of Chicago Press.

Ramírez, M.C. (1996). Brokering Identities: Art Curators and the Politics of Cultural Representation. En Greenberg, R.; Ferguson, B. y Nairne, S. (Eds.), Thinking about Exhibitions (15-27). Londres: Routledge.

Rodríguez, B. (1992) ¡Esta no es otra bienal! En Herrera, P. (ed.), Primera Bienal de Pintura del Caribe y Centroamérica. (17-19). Santo Domingo: Museo de Arte Moderno.

Tolentino, M. (1992). Historia y prehistoria de la Primera Bienal de Pintura del Caribe. En Herrera, P. (ed.), Primera Bienal de Pintura del Caribe y Centroamérica (19-24). Santo Domingo: Museo de Arte Moderno.

Tolentino, M. (1999). La vida urbana en la región del Caribe. Santo Domingo: Centro Cultural Cariforo.

Walcott, Derek (1995). The Antilles: Fragments of Epic Memory. En Lewis, S. y Hewitt, J. (Eds.), Caribbean Visions. Contemporary Painting and Sculpture (29 37). Alexandria: Art Services International.

Wood, Yolanda (1998). Arte del Caribe. Poéticas y estrategias de los 80 y los 90. En Zaya, A. y Borràs, M.L. (Eds.), Caribe Insular: Exclusión, Fragmentación y Paraíso (36-41). Badajoz: MEIAC.

Wood, Yolanda (2000). El decenio que terminó el siglo XX. Arte por Excelencias, 1, 13-20. 